\title{
Effect of nutrient starvation on proliferation and cytokine secretion of peripheral blood lymphocytes
}

\author{
YOSHIKO OTA, SOICHIRO ISHIHARA, KENSUKE OTANI, KOJI YASUDA, TAKESHI NISHIKAWA, \\ TOSHIAKI TANAKA, JUNICHIRO TANAKA, TOMOMICHI KIYOMATSU, KAZUSHIGE KAWAI, \\ KEISUKE HATA, HIROAKI NOZAWA, SHINSUKE KAZAMA, HIRONORI YAMAGUCHI, \\ EIJI SUNAMI, JOJI KITAYAMA and TOSHIAKI WATANABE
}

Department of Surgical Oncology, The University of Tokyo Hospital, Tokyo 113-8655, Japan

Received September 14, 2015; Accepted January 20, 2016

DOI: $10.3892 / \mathrm{mco} .2016 .763$

\begin{abstract}
Proliferating cancer cells are exposed to nutrient deprivation. Numerous previous studies have demonstrated how nutrient deprivation affects cancer cells; however, immune cells exposed to the identical conditions have not been completely examined. Furthermore, T-helper 2 lymphocyte predominance in certain neoplastic diseases has been reported; however, the mechanism remains unclear. The present study aimed to confirm whether nutrient deprivation affected proliferation and cytokine secretion of peripheral blood lymphocytes (PBLs). The proliferation of PBLs from healthy donors, cultured in a medium containing various glucose levels, was assessed by 3-(4,5-dimethylthiazol-2-yl)-5-(3-carboxymethoxyphenyl)-2(4-sulfophenyl)-2H-tetrazolium, inner salt (MTS) assay. The expression levels of interleukin (IL)-4 and interferon (IFN)- $\gamma$ among CD4(+) T cells, cultured with or without glucose and activated with phorbol 12-myristate 13-acetate and ionomycin, were examined using an intracellular cytokine staining method. The proliferation of PBLs cultured in a medium containing $<100 \mathrm{mg} / \mathrm{dl}$ glucose of the standard blood sugar (BS) level was significantly reduced compared with the proliferation observed in a medium containing a standard BS level or higher. PBLs cultured in a glucose-free medium contained a significantly higher percentage of IL-4-positive and a lower percentage of IFN- $\gamma$-positive CD4(+) T cells compared with those cultured in a high-glucose medium. Nutrient deprivation suppressed the proliferation of PBLs, fostered the secretion of IL-4 and reduced secretion of IFN- $\gamma$. It is therefore possible that glucose-deficient microenvironments in local cancer tissues cause a partial immunodeficiency, which is advantageous to cancer growth.
\end{abstract}

Correspondence to: Dr Yoshiko Ota, Department of Surgical Oncology, The University of Tokyo Hospital, 7-3-1 Hongo, Bunkyo-ku, Tokyo 113-8655, Japan

E-mail: kikkawa-tky@umin.ac.jp

Key words: peripheral blood lymphocyte, nutrient starvation, glucose, proliferation, cytokine, IL- 4 , IFN- $\gamma$, Th2 predominance

\section{Introduction}

Growing tumor tissues require nutrients, which are supplied by the increased blood flow caused by tumor angiogenesis. However, the glucose level is frequently reduced in local tumor tissues $(1,2)$, suggesting that proliferating cancer cells are exposed to nutrient deprivation. Numerous previous studies have shown how cancer cells survive under these conditions (3-6).

It is generally suggested that cancer growth causes a host immune response, although it is often insufficient for immune function. Various mechanisms have been proposed to explain this immunosuppression, including the inhibition of T-cell function by immunosuppressive factors (7-10). $\mathrm{T}$ lymphocytes produce various cytokines, which serve important roles in the immune system. Completely differentiated T-helper (Th) lymphocytes are divided into at least two subtypes, Th1 and Th2. Th1 lymphocytes secrete cytokines, including interleukin (IL)-2 and interferon (IFN) $-\gamma$, which activate cytotoxic $\mathrm{T}$ lymphocytes and macrophages, and also tumor necrosis factor $\beta$, which is associated with tumor injury. Th2 cells secrete cytokines, including IL-4, IL-5 and IL-6, which induce B cell differentiation, which is associated with antibody production (11-15). Th1/Th2 imbalance has been reported to be associated with various diseases. For example, Th1 predominance is reported in rheumatoid arthritis (16), whereas Th2 predominance is reported in certain neoplastic diseases, including basal cell carcinoma $(17,18)$, multiple myeloma (19), and colon cancer $(20,21)$. However, the mechanisms underlying these imbalances remain to be elucidated.

While cancer cells proliferate, immune cells are also exposed to the identical condition of nutrient deprivation. It remains to be investigated how nutrient deprivation affects immune cells. One possible mechanism of cancer-mediated immunosuppression is that starved microenvironments have a detrimental effect on the proliferation and cytokine secretion by immune cells. To assess this hypothesis, the present study examined how peripheral blood lymphocytes (PBLs), obtained from healthy donors, proliferate under nutrient deprivation and whether this environment affects the secretion of intracellular cytokines by PBLs. 


\section{Materials and methods}

Cells and culture. PBLs were prepared from the venous blood of five healthy donors, which included two women and three men with a mean age of 39 years (range, 32-53 years). PBLs were isolated by density centrifugation on Ficoll-Paque PLUS (Amersham Biosciences, Buckinghamshire, UK) following washing three times $(250 \mathrm{x} \mathrm{g}$; $180 \mathrm{x} \mathrm{g}$; $120 \mathrm{x}$ g for $10 \mathrm{~min})$ with Dulbecco's modified Eagle's medium (DMEM; Sigma-Aldrich, St. Louis, MO, USA). The cells were suspended in $0.1 \%$ bovine serum albumin (BSA; Sigma-Aldrich) and antibiotics (Sigma-Aldrich), plus DMEM containing various glucose concentrations. The cells were cultured in 96- or 6-well plates coated with $5 \mu \mathrm{g} / \mathrm{ml}$ mouse anti-human cluster of differentiation (CD)3 monoclonal antibody (Bay Bioscience, Kobe, Japan) at $4^{\circ} \mathrm{C}$ overnight to select for $\mathrm{T}$ cells. The cells were subsequently washed with DMEM three times prior to culturing at $37^{\circ} \mathrm{C}$ in a humidified atmosphere containing $5 \% \mathrm{CO}_{2}$.

3-(4,5-Dimethylthiazol-2-yl)-5-(3-carboxymethoxyphenyl)-2 -(4-sulfophenyl)-2H-tetrazolium, inner salt (MTS)-based cell growth assay. The PBLs were seeded onto anti-CD3-coated 96-well, flat-bottomed microtiter plates at a density of $2 \times 10^{5}$ cells/well and cultured in DMEM, supplemented with $0.1 \%$ BSA and antibiotics, containing glucose at various concentrations $(0,25,50,100,225$ and $450 \mathrm{mg} / \mathrm{dl})$. The cells were cultured at $37^{\circ} \mathrm{C}$ under a humidified atmosphere containing $5 \% \mathrm{CO}_{2}$ for 3 days. The PBLs were subsequently incubated for $2 \mathrm{~h}$ with MTS solution, containing the electron-coupling reagent, phenazine methosulfate (Promega KK, Tokyo, Japan), at a final concentration of $10 \%$. Following a $2 \mathrm{~h}$ incubation period, cell vitality was assessed by measuring the absorbance $(490 \mathrm{~nm})$ of each well using a microplate reader (ImmunoMini NJ-2300; Japan Inter Med Co., Ltd., Tokyo, Japan).

Monoclonal antibodies (mAb). Fluorescein isothiocyanate (FITC)-conjugated mouse anti-human CD4 mAb (cat. no. 555346), phycoerythrin (PE)-conjugated mouse anti-human IL-4 mAb (cat. no. 559333) and phycoerythrin (PE)-conjugated IFN- $\gamma$ mAb (cat. no. 554701; all mouse IgG1), and FITC-mouse IgG1 (cat. no. 349041) and PE-mouse IgG1 (cat. no. 349043) were purchased from Becton Dickinson (San Jose, CA, USA).

Staining and flow cytometry. PBLs were seeded into anti-CD3-coated 6-well flat-bottomed microtiter plates in DMEM,containing either $450 \mathrm{mg} / \mathrm{dl}$ or no glucose, supplemented with $0.1 \%$ BSA and antibiotics at a density of $1 \times 10^{7}$ cells/well. The cells were cultured at $37^{\circ} \mathrm{C}$ under a humidified atmosphere containing $5 \% \mathrm{CO}_{2}$. Following culturing for 3 days, the cells were suspended in DMEM containing either $450 \mathrm{mg} / \mathrm{dl}$ or no glucose, supplemented with $0.1 \%$ BSA, antibiotics and a $2 \mu \mathrm{M}$ final concentration of GolgiStop, an intracellular protein transport inhibitor containing monensin (Becton Dickinson) for $6 \mathrm{~h}$. The cells were subsequently incubated with $50 \mathrm{ng} / \mathrm{ml}$ phorbol $12-\mathrm{m}$ yristate 13-acetate (PMA; Sigma-Aldrich) and $250 \mathrm{ng} / \mathrm{ml}$ ionomycin (Sigma-Aldrich) under an atmosphere containing $5 \% \mathrm{CO}_{2}$ at $37^{\circ} \mathrm{C}$. Following incubation for $6 \mathrm{~h}$, the cells were harvested and washed once with phosphate-buffered saline. The staining

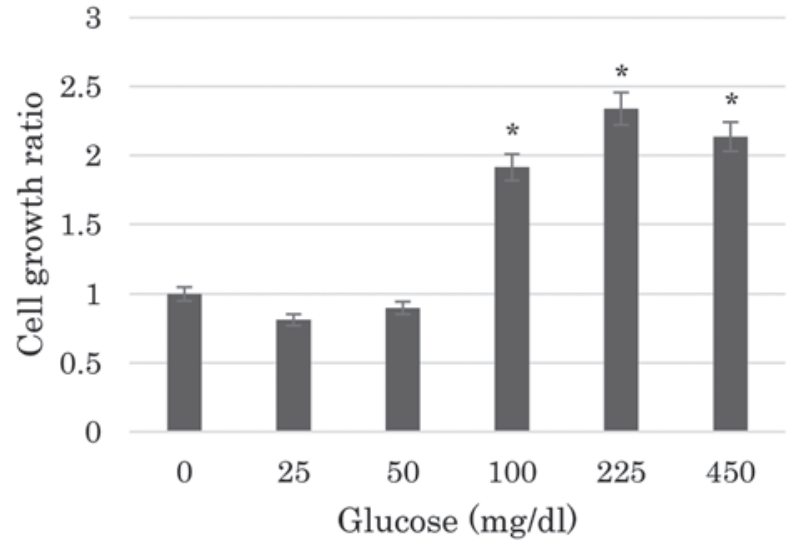

Figure 1. Peripheral blood lymphocyte proliferation in media containing various concentrations of glucose. The cell growth ratios represent the ratio of cells cultured in glucose-containing medium against the cells cultured in no glucose medium. The data are presented as the mean \pm standard deviation $\left({ }^{*} \mathrm{P}<0.05\right)$ of three independent experiments containing five replicates, using Tukey's test.

of cell surface antigens, including CD4, was performed prior to fixation and permeabilization for staining of intracellular cytokines. The cells were suspended in a fixation buffer (BioLegend, San Diego, CA, USA) at room temperature for $20 \mathrm{~min}$. Following centrifugation at $350 \mathrm{x}$ g for $5 \mathrm{~min}$ at $37^{\circ} \mathrm{C}$, the fixed cells were resuspended in a permeabilization wash buffer (BioLegend) and centrifuged twice at $350 \mathrm{xg}$ for $5 \mathrm{~min}$. Following permeabilization, the cells were stained with mAbs-targeting intracellular cytokines, including IL-4 and IFN- $\gamma$. The cells were analyzed by flow cytometry (FACSCalibur; BD Biosciences, Franklin Lakes, NJ, USA). Lymphocytes were gated by forward scatter and side scatter, and then CD4(+) cells were gated by FITC intensity. The cytokine expression ratio in the CD4(+) cells was determined using the PE intensity.

Statistical analysis. All statistcal analyses were performed using SPSS version 16.0 (IBM SPSS, Chicago, IL, USA). The data were analyzed for statistical significance using the Tukey's test and Student's t-test. $\mathrm{P}<0.05$ was considered to indicate a statistically significant difference.

\section{Results}

The present study first assessed the effects of nutrient deprivation on the proliferation of PBLs using an MTS assay. As shown in Fig. 1, the proliferation of PBLs was significantly reduced in media containing no glucose or a low glucose level compared with that in media containing $\geq 100 \mathrm{gm} / \mathrm{dl}$ glucose. The proliferation of PBLs in media containing 25 or $50 \mathrm{mg} / \mathrm{dl}$ glucose was significantly reduced to the identical level as that in media containing $0 \mathrm{mg} / \mathrm{dl}$ glucose $(\mathrm{P}<0.001)$. The differences in the proliferation of PBLs among the media containing 0,25 or $50 \mathrm{mg} / \mathrm{dl}$ glucose were not statistically significant. Similarly, the proliferation of PBLs was not significantly different in media containing 100,225 or $450 \mathrm{mg} / \mathrm{dl}$ glucose.

Next, the present study compared cytokine secretion by PBLs cultured in a high glucose-containing medium and a glucose-deprived medium. The immunostaining patterns of 
A
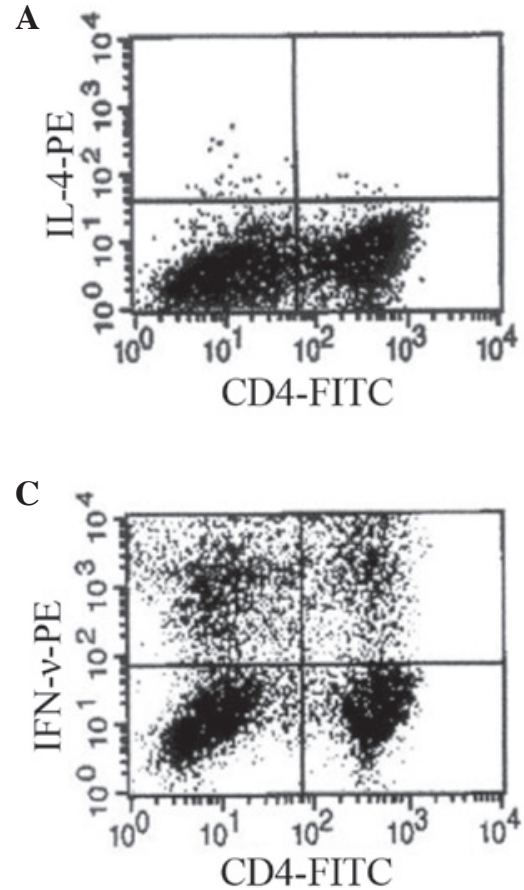

B

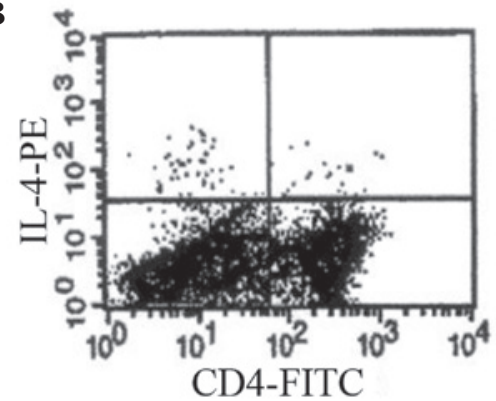

D

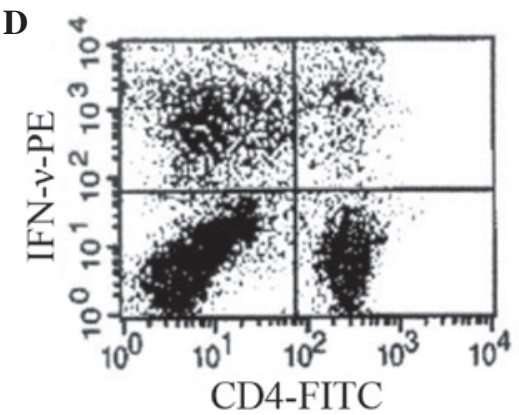

Figure 2. Dot plot patterns of intracellular cytokine staining in peripheral blood lymphocytes. The intensity of FITC-labelled CD4 was plotted along the X-axis and the intensity of PE-labelled (A and B) IL-4 and (C and D) IFN- $\gamma$ was plotted along the y-axis, following culturing with either (A and C) 450 mg/dl glucose or (B and D) no glucose. The upper left quadrant shows CD4(-) and IL-4/IFN- $\gamma(+)$, the lower left quadrant shows CD4(-) and IL-4/IFN- $\gamma(-)$, the upper right quadrant shows CD4(+) and IL-4/IFN- $\gamma(+)$ and the lower right quadrant shows CD4(+) and IL-4/IFN- $\gamma(-)$. CD, cluster of differentiation; IL, interleukin; IFN, interferon; PE, phycoerythrin; FITC, fluorescein isothiocyanate.

intracellular cytokines induced by the activation with PMA and ionomycin were examined in CD4(+) cell populations. The frequency of cytokine-positive cells reached a maximum following $6 \mathrm{~h}$ of stimulation and gradually decreased thereafter (data not shown). Therefore, the cytokine expression following $6 \mathrm{~h}$ of stimulation was examined in subsequent experiments. Fig. 2 demonstrates the representative dot plot analyses of intracellular cytokines following culturing with or without high levels of glucose. The percentages of cytokine-positive cells in CD4(+) T-cell populations are listed in Table I. Cells cultured in no-glucose medium contained a significantly higher percentage of IL-4-positive CD4(+) $\mathrm{T}$ cells compared with those cultured in high-glucose medium $(0.30 \pm 0.05$ vs. $0.12 \pm 0.10 \% ; P=0.049)$. However, the percentage of IFN- $\gamma$-positive CD4(+) T cells significantly decreased in cells cultured in no glucose medium compared with those cultured in high-glucose medium $(6.39 \pm 0.56$ vs. $15.37 \pm 3.14 \%$; $\mathrm{P}=0.008)$.

\section{Discussion}

The present study demonstrated that low glucose levels in the culture medium had a detrimental effect on the proliferation of PBLs. The majority of previous studies have reported that nutrient deprivation affects the growth of cancer cells $(4,5)$; however, immune cells exposed to the identical conditions remain to be examined in detail. In the present data, the proliferation of PBLs in media containing glucose concentrations less than the standard blood sugar (BS) level was significantly restrained compared with that in the media containing glucose concentrations of the standard BS level or higher. The proliferation ratio of PBLs was not directly proportional to the glucose
Table I. Percentage of cytokine-positive cells among CD4(+) peripheral blood lymphocytes cultured in high or no glucose medium following stimulation with phorbol 12-myristate 13-acetate and ionomycin.

\begin{tabular}{lcc}
\hline & \multicolumn{2}{c}{ Percentage of positive cells } \\
\cline { 2 - 3 } Glucose & Interleukin-4 & Interferon- $\gamma$ \\
\hline High & $0.12 \pm 0.10$ & $15.37 \pm 3.14$ \\
No & $0.30 \pm 0.05^{\mathrm{a}}$ & $6.39 \pm 0.56^{\mathrm{a}}$
\end{tabular}

Intracellular cytokine expression was analyzed by flow cytometry. The data represent the mean \pm standard deviation of cells positive for each cytokine among the $\mathrm{CD} 4(+) \mathrm{T}$ cell population $\left({ }^{\mathrm{a}} \mathrm{P}<0.05\right) . \mathrm{CD}$, cluster of differentiation.

level of the medium. It appeared that standard BS level was a boundary; media containing glucose concentrations that were higher or lower than the standard BS level resulted in different levels of cell growth. In vivo, cancer cells tend to colonize and establish angiogenesis to supply energy. However, it is hypothesized that insufficient vascular structure produces local nutrient-starved microenvironments. Therefore, it is possible that local glucose deficiencies interfere with immune cell function, making it ineffective against cancer.

Furthermore, the present study demonstrated that nutrient starvation affected PBL cytokine secretion. Several previous studies have reported that certain diseases exhibit a Th1/Th2 imbalance, and Th2 predominance has been observed in certain neoplastic diseases $(20,21)$. A previous study revealed 
that IL-2 and IFN- $\gamma$ were downregulated in PBLs of patients with gastrointestinal cancer (22). Another previous study demonstrated that the frequency of IL-4-producing cells only slightly increased in CD4(+) peripheral blood mononuclear cells of various patients with cancer, whereas the frequency of IFN- $\gamma$-producing cells decreased (23). The present experiments indicated that glucose deficiency fostered the secretion of IL-4 and interfered with the secretion of IFN- $\gamma$ in CD4(+) PBLs of healthy donors. Th2 cells secreted IL-4; therefore, the increased frequency of IL-4-producing cells suggests an increase in the number of Th2 cells, at least in part. By contrast, Th1 cells secreted IFN- $\gamma$; therefore, the decreased frequency of IFN- $\gamma$-producing cells may be a result of a decrease in the number of Th1 cells. The present results are consistent with previous reports revealing Th2 predominance in malignant diseases. Although the reason for Th2 predominance in neoplastic diseases remains to be elucidated, it is possible that glucose-deficient microenvironments in local cancer tissues are associated with Th2 predominance in malignant diseases. Th2 predominance or Th1 dysfunction means that the cytotoxic immune system does not effectively function, and this is hypothesized to be advantageous for cancer growth.

The present study attempted to determine the association between immune cells and their surroundings, particularly glucose suppression. However, the environment encircling immune cells comprises various conditions, including nutrient depression and hypoxia. Proliferating cancer cells require oxygen and nutrients; however, tumor vessels cannot supply them with sufficient oxygen $(1,2)$. In addition, nutrient starvation is associated with various factors, including glucose, amino acids and serum. These factors are hypothesized to affect the growth and functions of immune cells. Therefore, limitations exist to the explanation of immunosuppression by glucose depression alone. Although the present study regarded proliferation and cytokine secretion of immune cells as indexes of immune system function, immune cells have other diverse functions and further research is required. Furthermore, a fundamental limitation to the present study is the possibility that PBLs from healthy donors are different from PBLs from patients with cancer.

In conclusion, glucose deficiency has an effect on the proliferation of PBLs and their secretion of cytokines. The proliferation of PBLs cultured in medium containing $<100 \mathrm{mg} / \mathrm{dl}$ glucose was significantly reduced compared with the proliferation of PBLs cultured in a medium containing a standard blood sugar level or greater. Furthermore, a glucose-deprived environment increases the frequency of IL-4-producing cells among the CD4(+) PBLs of healthy donors and decreases the frequency of IFN- $\gamma$-producing cells. These results indicated that the local immunosuppressive conditions and Th2 predominance in malignant diseases are partly due to the microenvironment surrounding cancer, including glucose deprivation.

\section{References}

1. Jain RK: Molecular regulation of vessel maturation. Nat Med 9: 685-693, 2003

2. Vaupel P, Thews O and Hoeckel M: Treatment resistance of solid tumors: Role of hypoxia and anemia. Med Oncol 18: 243-259, 2001.
3. Park HR, Tomida A, Sato S, Tsukumo Y, Yun J, Yamori T, Hayakawa Y, Tsuruo T and Shin-ya K: Effect on tumor cells of blocking survival response to glucose deprivation. J Natl Cancer Inst 96: 1300-1310, 2004.

4. He L, Li X, Luo HS, Rong H and Cai J: Possible mechanism for the regulation of glucose on proliferation, inhibition and apoptosis of colon cancer cells induced by sodium butyrate. World J Gastroenterol 13: 4015-4018, 2007.

5. Sato K, Tsuchihara K, Fujii S, Sugiyama M, Goya T, Atomi Y, Ueno T, Ochiai A and Esumi H: Autophagy is activated in colorectal cancer cells and contributes to the tolerance to nutrient deprivation. Cancr Res 67: 9677-9684, 2007.

6. Ferraro E and Cecconi F: Autophagic and apoptotic response to stress signals in mammalian cells. Arch Biochem Biophys 462: 210-219, 2007.

7. Naor D: Suppressor cells: Permitters and promoters of malignancy? Adv Cancer Res 29: 45-125, 1979.

8. Fearon ER, Pardoll DM, Itaya D, Golumbek P, Levitsky HI, Simons JW, Karasuyama H, Vogelstein B and Frost P: Interleukin-2 production by tumor cells bypasses $\mathrm{T}$ helper function in the generation of an antitumor response. Cell 60: 397-403, 1990.

9. Tada T, Ohzeki S, Utsumi K, Takiuchi H, Muramatsu M, Li XF, Shimizu J, Fujiwara $\mathrm{H}$ and Hamaoka T: Transforming growth factor-beta-induced inhibition of T cell function. Susceptibility difference in $\mathrm{T}$ cells of various phenotypes and functions and its relevance to immunosuppression in the tumor-bearing state. J Immunol 146: 1077-1082, 1991.

10. Gallimore A and Sakaguchi S: Regelation of tumour immunity by CD25+T cells. Immunology 107: 5-9, 2002.

11. Mosmann TR, Cherwinski H, Bond MW, Giedlin MA and Coffman RL: Two types of murine helper T cell clone. I. Definition according to profiles of lymphokine activities and secreted proteins. J Immunol 136: 2348-2357, 1986.

12. Bottomly K: A functional dichotomy in CD4+ T lymphocytes. Immunol Today 9: 268-273, 1988.

13. Mossman TR and Coffman RL: TH1 and TH2 cells: Different patterns of lymphokine secretion lead to different functional properties. Annu Rev Immunol 7: 145-173, 1989.

14. Kupfer A and Singer SJ: Cell biology of cytotoxic and helper T cell functions. Annu Rev Immunol 7: 309-337, 1989.

15. Romagnani S: Lymphokine production by human $\mathrm{T}$ cells in dease state. Annu Rev Immunol 12: 227-257, 1994.

16. Berner B, Akça D, Jung T, Muller GA and Reuss-Borst MA: Analysis of Th1 and Th2 cytokines expressing CD4+ and CD8+ T cells in rheumatoid arthritis by flow cytometry. J Rheumatol 27: 1128-1135, 2000

17. Kim J, Modlin RL, Moy RL, Dubinett SM, McHugh T, Nickoloff BJ and Uyemura K: IL-10 production in cutaneous basal and squamous cell carcinoma. A mechanism for evading the local T cell immune response. J Immunol 155: 2240-2247, 1995.

18. Elsässer-Beile U, von Kleist S, Stähle W, et al: Cytikine levels in whole blood cell cultures as parameters of the cellular immunologic activity in patients with malignant melanoma and basal cell carcinoma. Cancer 71: 231-236, 1993

19. Hata H, Xiao H, Petrucci MT, Woodliff J, Chang R and Epstein J: Interleukin-6 gene expression in multiple myeloma: A characteristic of immature tumor cells. Blood 81: 3357-3364, 1993.

20. Pellegrini P, Berghella AM, Del Beato T, Cicia S, Adorno D and Casciani CU: Disregulation in TH1 and TH2 subsets of CD4+ $\mathrm{T}$ cells in peripheral blood of colorectal cancer patients and involvement in cancer establishment and progression. Cancer Immunol Immunother 42: 1-8, 1996.

21. Berghella AM, Pellegrini P, Del Beato T, Marini M, Tomei E, Adorno D and Casciani CU: The significance of an increase in soluble interleukin-2 receptor level in colorectal cancer and its biological regulating role in the physiological switching of the immune response cytokine network from TH1 to TH2 and back. Cancer Immunol Immunother 45: 241-249, 1998.

22. Nakayama H,Kitayama J,Muto T and Nagawa H: Characterization of intracellular cytokine profile of CD4(+) T cells in peripheral blood and tumor-draining lymph nodes of patients with gastrointestinal cancer. Jpn J Clin Oncol 30: 301-305, 2000.

23. Sato M, Goto S, Kaneko R, Ito M, Sato S and Takeuchi S: Impaired production of Th1 cytokines and increased frequency of Th2 subsets in PBMC from advanced cancer patients. Anticancer Res 18: 3951-3955, 1998. 